\title{
Segmented Neutrophils to Neutrophils Ratio Measurement
}

National Cancer Institute

\section{Source}

National Cancer Institute. Segmented Neutrophils to Neutrophils Ratio Measurement. NCI Thesaurus. Code C120643.

The determination of the ratio of segmented neutrophils compared to neutrophils present in a sample. The measurement may be expressed as a ratio or percentage. 